\title{
Effects of Humulus lupulus extract or its Components on Viability, Lipid Peroxidation, and expression of Vascular Endothelial Growth Factor in Melanoma Cells and Fibroblasts
}

\author{
Neena Philips ${ }^{1 \star}$, Philips Samuel ${ }^{2}$, Tiana Lozano ${ }^{1}$, Ana Gvaladze ${ }^{1}$, Benito Guzman ${ }^{1}$, Halyna Siomyk ${ }^{1}$ and Gerhard Haas ${ }^{1}$ \\ ${ }^{\prime}$ Department of Biology, Fairleigh Dickinson University, Teaneck, NJ, USA \\ ${ }^{2}$ Department of Computer Science, University of Virginia, Charlottesville, VA, USA
}

\section{Article Info}

*Corresponding author:

\section{Neena Philips}

Professor of Biology

Fairleigh Dickinson University

$\mathrm{H}-\mathrm{DH} 4-03$

1000 River Road

Teaneck, NJ 07666

USA

Tel: 2016926494

E-mail: nphilips@fdu.edu neenaphilips@optonline.net

Received: July 18, 2017

Accepted: August 21, 2017

Published: August 28, 2017

Citation: Philips N, Samuel P, Lozano T, et al. Effects of Humulus lupulus extract or its Components on Viability, Lipid Peroxidation, and expression of Vascular Endothelial Growth Factor in Melanoma Cells and Fibroblasts. Madridge J Clin Res. 2017; 1(1): 15-19. doi: $10.18689 / \mathrm{mjcr}-1000103$

Copyright: (c) 2017 The Author(s). This work is licensed under a Creative Commons Attribution 4.0 International License, which permits unrestricted use, distribution, and reproduction in any medium, provided the original work is properly cited.

Published by Madridge Publishers

\begin{abstract}
Cancer and aging are associated with altered cell viability and angiogenesis, which is mediated by vascular endothelial growth factor (VEGF). These alterations have been associated with cellular oxidative stress. Humuluslupulus (HOP) extract, and its components, which include alpha-acid, beta-acid, xanthoflavonoids, xanthohumunol, and isoxanthohumunol, exhibit antioxidant activity. This research examined the effects of HOP extract or its components on direct antioxidant activity, and on cell viability, lipid peroxidation, and expression of VEGF in melanoma cells, and dermal fibroblasts. The HOP extract, and its components exhibited direct antioxidant activity. In melanoma cells, HOP extract, and its components significantly inhibited cell viability and stimulated extracellular lipid hydroperoxides at all examined concentrations; and with few exceptions did not significantly alter intracellular lipid peroxidation or the expression of VEGF. In dermal fibroblasts, HOP extract and its components significantly inhibited cell viability and intracellular lipid peroxidation, and stimulated the expression at VEGF at the highest examined concentration; and with few exceptions did not significantly alter extracellular lipid peroxidation. It is inferred that HOP extract, and its components differentially and beneficially regulate the cellular biochemistry of melanoma cells, and fibroblasts for the management of cancer, and aging.
\end{abstract}

Keywords: Humulus lupulus; Melanoma; Fibroblasts; Cell Viability; Lipid Peroxidation; Vascular Endothelial Growth Factor.

\section{Introduction}

Carcinogenesis and aging are associated with alterations in cell viability, cell migration, angiogenesis, and extracellular matrix (ECM), which is predominantly synthesized by dermal fibroblasts [1-8]. While carcinogenesis and aging involve increased ECM proteolysis, cancer is associated with increased cell survival and angiogenesis, and aging is associated with reduced cell viability and angiogenesis, which is mediated by several factors including vascular endothelial growth factor (VEGF) [1-8]. Oxidative stress plays a key role in aging and carcinogenesis [1-5]. The reactive oxygen species (ROS) cause oxidative damage to DNA, proteins and lipids, which includes lipid peroxidation [2-4]. 
Antioxidants modulate carcinogenesis and aging by changing the redox environment of the cells $[2-4,9,10]$. Phenolic compounds serve as antioxidants, primarily because of their hydroxyl groups [1-5]. Nicotimamide and its hydroxyl derivatives increase fibrillar collagen, and exhibit direct antioxidant activity [1]. Ascorbate at lower concentrations inhibits cancer cell viability by inducing cell apoptosis $[7,8]$. The mechanism of ascorbate mediated cancer cell death is the generation of hydrogen peroxide, for antioxidants can have pro-oxidant effects in cells through Fenton or Haber-Weiss reactions $[10,11]$.

Humuluslupulus(HOP) extract is rich in phenolic compounds, its components include alpha-acid (humulone), beta-acid (lupulone), xanthoflavonoids, xanthohumunol and isoxanthohumunol [12-18]. The HOP extract or its components possess antioxidant and anticarcinogenic properties, through the stimulation of apoptosis and inhibition of angiogenesis [13-18]. Humulone prevents angiogenesis in embryo chorioallantoic membranes, and inhibits the expression of VEGF in endothelial and tumor cells [13]. Lupulone derivatives or lupulone induce apoptosis in prostate cancer or colon cancer cells $[14,15]$. The induction of apoptosis by lupulone is through p38 pathway mediated stimulation of p53 and TRAILdeath receptor expression [15]. Further, lupulone inhibits angiogenic potential of endothelial cells [16]. Xanthohumol inhibits cancer cell proliferation, and angiogenic potential of endothelial cells, through the inhibition of NF-kB and Akt pathways $[17,18]$. We have reported the stimulation of fibrillar collagen and direct inhibition of proteolytic enzymes by xanthohumol [6].

The mechanisms of the effects of HOP extract or its components on melanoma, or on dermal fibroblasts have not been reported. The goal of this research was to determine the direct antioxidant activity of HOP extract or its components, and its effects on cell viability, extracellular and intracellular lipid peroxidation, and the expression of VEGF in melanoma cells, and dermal fibroblasts.

\section{Materials and Methods}

\section{Antioxidant Activity}

The direct antioxidant activity of HOP extract or its components was determined by $\mathrm{ABTS}^{\oplus}\left(2,2^{\prime}\right.$-azino-di-[3ethylbenzthiazoline sulphonate]) assay, based on the inhibition of the oxidation of $\mathrm{ABTS}^{\circledR}$ to $\mathrm{ABTS}^{\oplus}$ radical by metmyoglobin by antioxidants (Cayman Chemical Antioxidant Assay kit) [1]. HOP extract or its components (alpha-acid, beta-acid, xanthoflavonoids, xanthohumunol and isoxanthohumunol) at $0,0.01,0.04,0.02$ or $1 \%$ of respective $50 \mathrm{mg} / \mathrm{ml}$ stock solutions, was incubated with $A B T S$ and metmyoglobin and the inhibition of ABTS oxidation was measured spectrophotometrically at $405 \mathrm{~nm}$. The HOP extract and its components were obtained from S. S. Steiner, Inc

\section{Cell Culture}

Melanoma cells (CRL-1619, American Tissue Cell Culture), and human neonatal dermal fibroblasts (Cascade Biologics) were cultured in Dulbecco's Modified Eagle's Medium (DMEM) supplemented with $10 \%$ heat inactivated fetal bovine serum and $1 \%$ penicillin/streptomycin (Life Technologies) $[1,6-8]$. Melanoma or fibroblasts cells were incubated with $0,0.01$, 0.04 or $0.02 \% \mathrm{HOP}$ extract or its components in experimental media composed of DMEM supplemented with $3 \%$ heat inactivated fetal bovine serum for 24 hours. The cells were examined for cell viability and intracellular lipid hydro peroxides. The extracellular media were examined for extracellular hydro peroxides and VEGF protein.

\section{Cell Viability}

The cells were examined for cell viability by "CellTiter $96{ }^{\circledR}$ $\mathrm{AQ}_{\text {ueous }}$ One Solution Cell Proliferation Assay System" (MTS), based on the reduction of MTS ["tetrazolium compound (3-(4,5-dimethylthiazol-2-yl)-5-(3-carboxymethoxyphenyl)-2(4-sulfophenyl)-2H-tetrazolium, inner salt; MTS) and an electron coupling reagent (phenazineethosulfate; PES)"] by viable cells to a brown color (Promega) $[1,6-8]$. The cells were incubated with MTS solution, and the reaction was measured spectrophotmetrically at $490 \mathrm{~nm}$ (Promega).

\section{Lipid Peroxidation}

The hydroperoxides, formed as a result of lipid peroxidation, were measured using PeroxiDetect kit (Sigma), which is based on the oxidation of ferrous to ferric ion by peroxides and the subsequent reaction of ferric ion with xylenol orange ("3,3'-bis[N,N-bis(carboxymethyl)aminomethyl] o-cresolsulfonephthalein, sodium salt") to a blue colored product (Sigma). Aliquots of cell lysates or media were incubated with ferrous/xylene orange solution and the reaction was measured spectrophotmetrically at $560 \mathrm{~nm}$ (Sigma).

\section{VEGF Protein Levels}

The VEGF protein levels were determined by indirect ELISA (Kirkguaard and Perry Laboratories Inc, Stressgen [1, 6, $7,8]$. The media were incubated with coating buffer in 96 well immunosorbent plates for 24 hours at $4^{\circ} \mathrm{C}$. The wells were blocked with bovine serum albumin, incubated with VEGF antibody for 24 hours at $4^{\circ} \mathrm{C}$, washed, incubated with secondary antibody for 1 hour at room temperature, washed and incubated with peroxidase substrate till color formation, which was read spectrophotometrically at $405 \mathrm{~nm}$ (Kirkguaard and Perry Laboratories Inc, Stressgen).

\section{Data Analysis}

The effects of each of the concentrations of HOP extract or its components were determined relative to control (without HOP extract or its components) at $100 \%$.The significant effects of each of the concentrations of the HOP extract or its components in each of the cells (melanoma or fibroblasts) were determined relative to control (without HOP extract or components) by ANOVA and student t-tests at $95 \%$ confidence interval. 


\section{Results}

\section{Direct inhibition of ABTS oxidation by HOP extract, and its components}

The HOP extract, and its components exhibited significant direct antioxidant activity $(p<0.05)$ (Figure 1$)$. Relative to control, 1\% HOP extract, alpha-acid, beta-acid, xanthoflavonoid, xanthohumol, and isoxanthohumol significantly inhibited ABTS oxidation to $75 \%, 32 \%, 51 \%, 66 \%, 60 \%$ and $91 \%$ of control, respectively $(p<0.05)$ (Figure 1$)$. In addition, $0.2 \%$ of HOP extract, alpha-acid, xanthohumol, and isoxanthohumol significantly inhibited ABTS oxidation to $46 \%$, $37 \%, 86 \%$, and $70 \%$ of control, respectively $(p<0.05)$ (Figure 1 ).

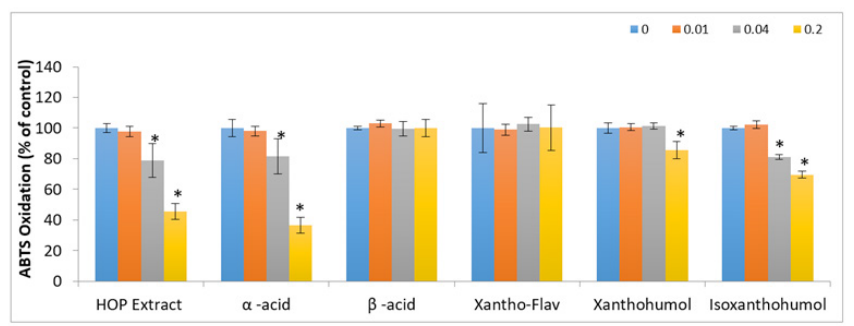

Figure 1. Direct effect of HOP extract, alpha-acid, beta-acid, xantho-flavonoid, xanthohumonol, and isoxanthohumnol at $0 \%$ (light blue), $0.01 \%$ (orange), $0.04 \%$ (grey), $0.2 \%$ (yellow), and 1\% (dark blue) on ABTS oxidation; error bars: standard deviation, $\mathrm{n}=4$; *: $p<0.05$, relative to control.

\section{Regulation of melanoma and fibroblast cell viability by HOP extract, and its components}

The HOP extract or its components significantly inhibited melanoma cell viability at each of the concentrations, 0.01 to $0.2 \%$; and fibroblast cell viability predominantly at the highest concentration, $0.2 \%(p<0.05)$ (Figure 2).

(A)

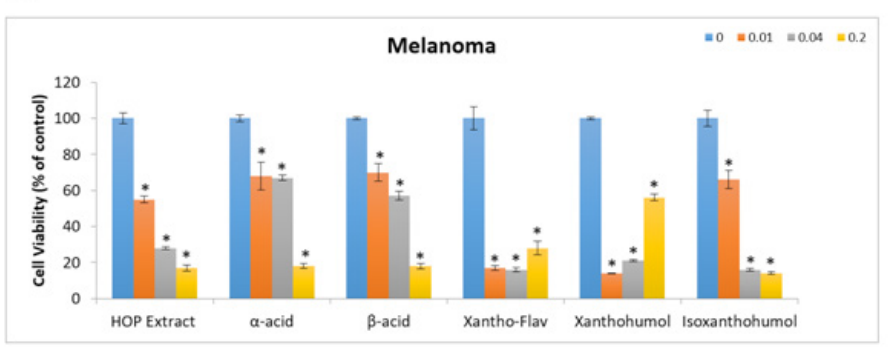

(B)

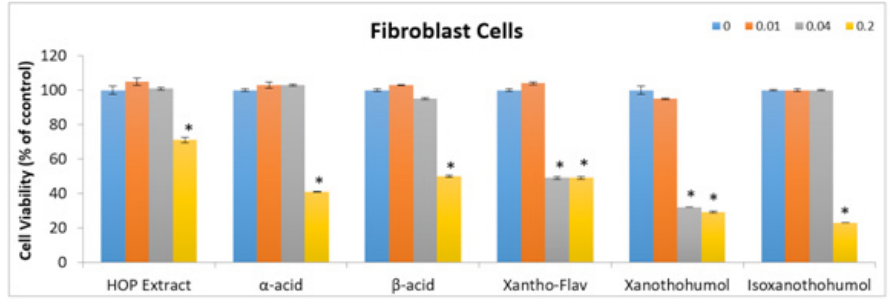

Figure 2. Effect of HOP extract, alpha-acid, beta-acid, xanthoflavonoid, xanthohumonol, and isoxanthohumnol at $0 \%$ (light blue), $0.01 \%$ (orange), $0.04 \%$ (grey), and $0.2 \%$ (yellow) on cell viability of melanoma cells $(A)$, and fibroblast cells $(B)$; error bars: standard deviation, $n=4 ;{ }^{*}: p<0.05$, relative to control.

In melanoma cells, $0.01,0.04,0.2 \%$ of HOP extract or each of its components, respectively, significantly inhibited cell viability as follows: HOP extract to $55 \%, 28 \%$, and $17 \%$ of control, alpha-acid to $68 \%, 67 \%$, and $18 \%$ of control, beta-acid to $70 \%, 57 \%$, and $18 \%$ of control, xantho-flavonoid to $17 \%, 16 \%$, and $28 \%$ of control, xanthohumol to $14 \%, 21 \%, 56 \%$ of control, and isoxanthohumol to $66 \%, 16 \%$, and $14 \%$ of control $(p<0.05)$ (Figure $2 A)$.

In fibroblasts, $0.2 \%$ HOP extract, alpha-acid, betaacid, xantho-flavonoid, xanthohumol, and isoxanthohumol significantly inhibited cell viability to $71 \%, 41 \%, 50 \%, 49 \%, 29 \%$, and $23 \%$ of control, respectively $(p<0.05) \quad$ (Figure $2 B)$. In addition, $0.04 \%$ xantho-flavonoid and xanthohumol significantly inhibited fibroblast cell viability to $49 \%$ and $32 \%$ of control, respectively $(p<0.05)$ (Figure $2 B)$.

\section{Regulation of melanoma and fibroblast extracellular hydroperoxides by HOP extract, and its components}

The HOP extract or its components significantly stimulated extracellular lipid hydroperoxides in melanoma cells at each of the concentrations, 0.01 to $0.2 \%$ (except xanthohumol at $0.01 \%)$; and in fibroblast cells at the highest concentration (exceptxantho-flavonoid, xanthohumol, and isoxanthohumol), $0.2 \%(p<0.05)$ (Figure 3$)$.

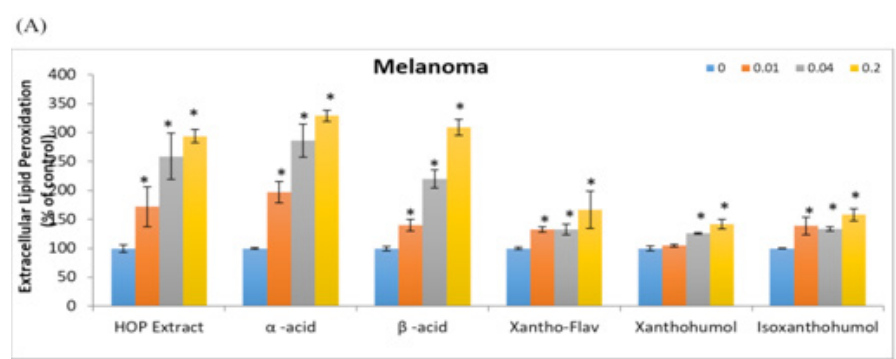

(B)

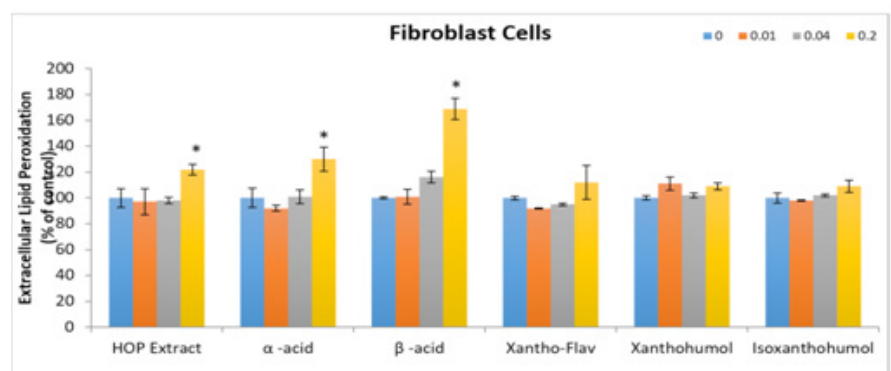

Figure 3. Effect of HOP extract, alpha-acid, beta-acid, xanthoflavonoid, xanthohumonol, and isoxanthohumnol at $0 \%$ (light blue), $0.01 \%$ (orange), $0.04 \%$ (grey), and $0.2 \%$ (yellow) on extracellular lipid peroxidation of melanoma cells (A), and fibroblast cells (B); error bars: standard deviation, $n=4 ;{ }^{*}: p<0.05$, relative to control.

In melanoma cells, $0.01,0.04,0.2 \%$ of HOP extract or each of its components, respectively, significantly inhibited cell viability as follows: HOP extract to $172 \%, 259 \%, 294 \%$ of control, alpha-acid to $197 \%, 286 \%, 329 \%$ of control, beta-acid to $140 \%, 220 \%, 309 \%$ of control, xantho-flavonoid to $133 \%$, $133 \%, 167 \%$ of control, and isoxanthohumol to $139 \%, 134 \%$, $158 \%$ of control $(p<0.05)$ (Figure $3 \mathrm{~A})$. Xanthohumol at 0.04 and $0.2 \%$ significantly stimulated extracellular hydroperoxides to $126 \%$, and $142 \%$ of control $(p<0.05)$ (Figure $3 A$ ). 
In fibroblasts, 0.2\% HOP extract, alpha-acid, and betaacid significantly stimulated extracellular hydroperoxides to $122 \%, 130 \%$, and $169 \%$ of control, respectively $(p<0.05)$ (Figure 3B).

\section{Regulation of melanoma and fibroblast intracellular hydroperoxides by HOP extract, and its components}

The HOP extract or its components did not significantly alter intracellular lipid hydroperoxides in melanoma cells (except xantho-flavonoid and xanthohumol at $0.2 \%$ ); and significantly inhibited it in fibroblast cells at the highest concentration, and in addition the second highest concentration for xantho-flavonoid, and xanthohumol $(p<0.05)$ (Figure 4).

(A)

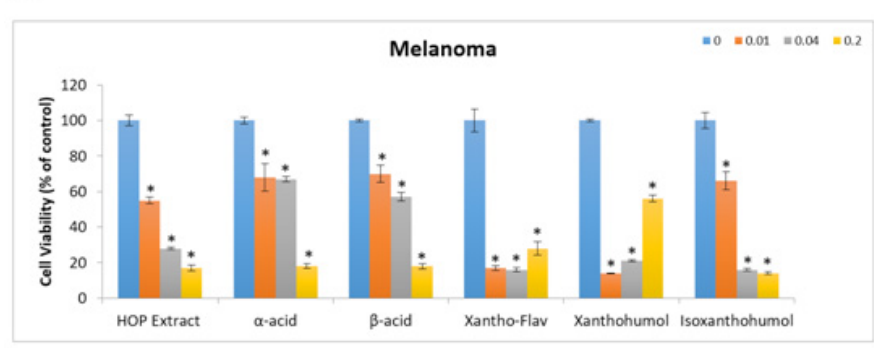

(B)

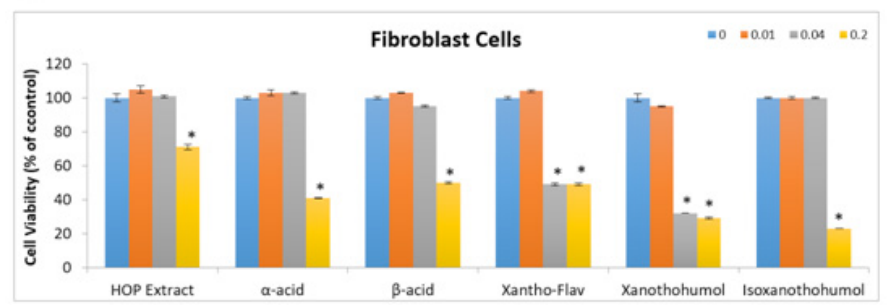

Figure 4. Effect of HOP extract, alpha-acid, beta-acid, xanthoflavonoid, xanthohumonol, and isoxanthohumnol at $0 \%$ (light blue), $0.01 \%$ (orange), $0.04 \%$ (grey), and $0.2 \%$ (yellow) on intracellular lipid peroxidation of melanoma cells (A), and fibroblast cells (B); error

bars: standard deviation, $n=4 ; *$ : $p<0.05$, relative to control.

In melanoma cells, $0.2 \%$ xantho-flavonoid and xanthohumol significantly stimulated intracellular hydroperoxides to $216 \%$ and $220 \%$ of control, respectively $(p<0.05)$ (Figure 4A).

In fibroblasts, 0.2\% HOP extract, alpha-acid, beta-acid, xantho-flavonoid, xanthohumol, and isoxanthohumol significantly inhibited intracellular lipid peroxides to $49 \%$, $40 \%, 35 \%, 81 \%, 61 \%$, and $39 \%$ of control, respectively $(p<0.05)$ (Figure 4B). In addition, $0.04 \%$ xantho-flavonoid and xanthohumol significantly inhibited intracellular lipid peroxides to $50 \%$ and $45 \%$ of control, respectively $(p<0.05)$ (Figure 4B).

\section{Regulation of melanoma and fibroblast VEGF expression by HOP extract, and its components}

The HOP extract or its components did not significantly alter VEGF expression in melanoma cells (except xanthoflavonoid); and significantly stimulated it in fibroblast cells at the highest concentration $(p<0.05)$ (Figure 5$)$.
(A)

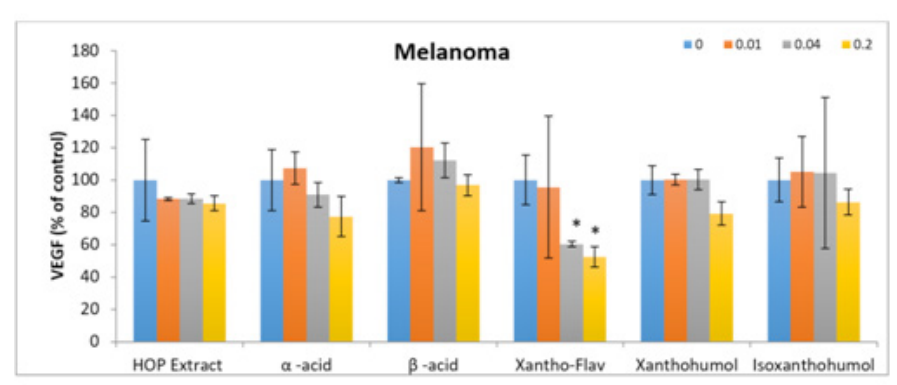

(B)

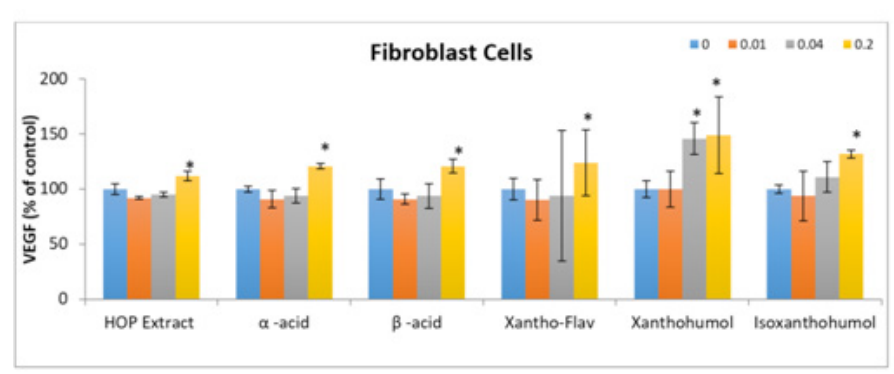

Figure 5. Effect of HOP extract, alpha-acid, beta-acid, xanthoflavonoid, xanthohumonol, and isoxanthohumnol at $0 \%$ (light blue), $0.01 \%$ (orange), $0.04 \%$ (grey), and $0.2 \%$ (yellow) on expression of VEGFin melanoma cells (A), and fibroblast cells (B); error bars: standard deviation, $n=4 ; *: p<0.05$, relative to control.

In melanoma cells, 0.04 and $0.2 \%$ of xantho-flavonoid significantly inhibited VEGF expression to $60 \%$ and $53 \%$ of control, respectively $(p<0.05)$ (Figure $5 A)$.

In fibroblasts, $1 \%$ HOP extract, alpha-acid, beta-acid, xantho-flavonoid, xanthohumol, and isoxanthohumol significantly stimulated VEGF expression to $112 \%, 121 \%, 121$ $\%, 124 \%, 149 \%$, and $132 \%$ of control, respectively $(p<0.05)$ (Figure 5B). In addition, $0.04 \%$ iso-xanthohumol significantly stimulated VEGF expression to $146 \%$ of control, respectively $(p<0.05)$ (Figure 5B).

\section{Discussion}

Carcinogenesis and aging are associated with altered cellular redox balance due to exposure to environmental pollutants or ultraviolet radiation, and genetics [1-5]. Phenolic compounds with their antioxidant property have potential to modulate the cellular redox environment and thereby carcinogenesis or aging [1-5]. The differential beneficial effects of HOP extract or its extracts in cancer versus normal cells are from their pro-oxidant versus antioxidant effects, respectively, in these cells. The potential for differential effects, in cancer versus normal cells, may be from differential cellular environment in cancer versus normal cells, such as the concentrations of metals that catalyze Fenton or Haber-Weiss reactions $[10,11]$. While the HOP extract, and its components exhibited direct antioxidant activity, they had differential beneficial effects in melanoma cells, and dermal fibroblasts.

Carcinogenesis is associated with increased cell proliferation, and angiogenesis [1-5]. The HOP extract or its components, from the smallest to the highest concentration examined, significantly inhibited melanoma cell viability and 
stimulated extracellular hydroperoxides, suggesting prooxidant mechanism in the inhibition of melanoma cell viability. In addition, xantho-flavonoid significantly inhibited the expression of VEGF in melanoma cells, suggesting antiangiogenic potential.

Aging is associated with loss of cell viability, and reduced angiogenesis [1-5]. The HOP extract or its components, at the highest concentration examined, significantly inhibited fibroblast cell viability and stimulated extracellular hydroperoxides, suggesting pro-oxidant mechanism. However, the HOP extract or its components significantly inhibited intracellular lipid peroxidation in fibroblast cells, suggesting cellular antioxidant activity; and significantly stimulated the expression of VEGF, suggesting angiogenic potential.

\section{Conclusion}

Carcinogenesis is associated with increased cell proliferation and angiogenesis, whereas aging is associated with reduced cell viability and angiogenesis. The melanoma cell viability was inhibited through pro-oxidant mechanism, at all concentrations of the HOP extract or its components; without antioxidant cellular effect or increased expression of VEGF. The fibroblasts cell viability was inhibited by prooxidant mechanism, at the highest concentration of HOP extract or its components, and was associated with increased cellular antioxidant activity and expression of VEGF.

\section{Acknowledgement}

This research was partially funded by S.S. Steiner,Inc, Madison Ave., NY, NY.

\section{References}

1. Philips N, Chalensouk KJ, Gonzalez S. Stimulation of the Fibrillar Collagen and Heat Shock Proteins by Nicotinamide or Its Derivatives in NonIrradiated or UVA Radiated Fibroblasts, and Direct Anti-Oxidant Activity of Nicotinamide Derivatives. Cosmetics. 2015; 2(2): 146-161. doi: 10.3390/ cosmetics 2020146

2. Bosch R, Philips N, Suárez PJ, et al. Mechanisms of Photoaging and Cutaneous Photocarcinogenesis, and Photoprotective Strategies with Phytochemicals. Antioxidants. 2015; 4(2): 248-268. doi: 10.3390/ antiox4020248

3. Philips $\mathrm{N}$, Siomyk $\mathrm{H}$, Jia $\mathrm{H}$, Parakandi $\mathrm{H}$. Inhibition of Angiogenesis in Cancer Management by Antioxidants. Anti-Angiogenesis Drug Discovery and Development. 2014; 132-146. doi: 10.1016/b978-0-12-8039632.50004-1

4. Philips N, Siomyk H, Bynum D, Gonzalez S. Skin Cancer, Polyphenols, and Oxidative Stress. Cancer. 2014; 265-270. doi: 10.1016/b978-0-12-4052055.00026-x
5. Philips N, Bynum D, Hwang H. Counteraction of Skin Inflammation and Aging or Cancer by Polyphenols and Flavonoids from Polypodiumleucotomos and Xanthohumol. Anti-Inflammatory \& Anti-Allergy Agents in Medicinal Chemistry. 2010; 9(2): 142-149. doi: 10.2174/187152310791110625

6. Philips $N$, Samuel $M$, Arena $R$, et al. Direct inhibition of elastase and matrixmetalloproteinases and stimulation of biosynthesis of fibrillar collagens, elastin, and fibrillins by xanthohumol. International Journal of Cosmetic Science. 2010; 32(5): 395-396. doi: 10.1111/j.1468-2494.2010.00609_4.x

7. Philips N, Dulaj L, Upadhya T. Cancer cell growth and extracellular matrix remodeling mechanism of ascorbate: beneficial modulation by $P$. leucotomos. Anticancer Res. 2009; 29(8): 3233-8.

8. Philips N, Keller T, Holmes C. Reciprocal effects of ascorbate on cancer cell growth and the expression of matrix metalloproteinases and transforming growth factor- $\beta$. Cancer Letters. 2007; 256(1): 49-55. doi: 10.1016/j. canlet.2007.05.009

9. Jacob C, Jamier V, Ba LA. Redox active secondary metabolites. Curr Opin Chem Biol. 2011; 15(1): 149-55. doi: 10.1016/j.cbpa.2010.10.015

10. Du J, Cullena JJ, Buettner GR. Ascorbic acid: Chemistry, biology and the treatment of cancer. BiochimBiophysActa . 2012; 1826(2): 443-457. doi: 10.1016/j.bbcan.2012.06.003

11. Chen Q, Espey MG, Krishna MC, et al. Pharmacologic ascorbic acid concentrations selectively kill cancer cells: Action as a pro-drug to deliver hydrogen peroxide to tissues. Proceedings of the National Academy of Sciences. 2005; 102(38): 13604-13609. doi:10.1073/pnas.0506390102

12. Karabín M, Hudcová $T$, Jelínek L, Dostálek P. Biologically Active Compounds from Hops and Prospects for Their Use. Comprehensive Reviews in Food Science and Food Safety. 2016; 15(3): 542-567. doi: 10.1111/1541-4337.12201

13. Shimamura $M$, Hazato $T$, Ashino $H$. Inhibition of angiogenesis by humulone, a bitter acid from beer hop. Biochemical and Biophysical Research Communications. 2001; 289(1): 220-224. doi: 10.1006/ bbrc.2001.5934

14. Mouratidis P, Colston K, Charolidi N, Pirianov G. Differential Role of Apoptosis and Autophagy Associated with Anticancer Effect of Lupulone (Hop $\beta$-Acid) Derivatives on Prostate Cancer Cells. Anti Cancer Agents in Medicinal Chemistry. 2014; 14(8): 1169-1178. doi: 10.2174/187152061466 6140623123006

15. Lamy V, Bousserouel S, Gosse F, Minker C, Lobstein A, Raul F. Lupulone triggers $p 38$ MAPK-controlled activation of $p 53$ and of the TRAIL receptor apoptotic pathway in human colon cancer-derived metastatic cells. Oncology reports. 2011; 26(1): 109114. doi: 10.3892/or.2011.1273

16. Siegel $L$, Miternique GA, Griffon $C$, et al. Antiangiogenic properties of lupulone, a bitter acid of HOP cones. Anticancer research, 2008; 28(1A): 289-294.

17. Gerhauser $C$, Hussong R, Bertl $E$, et al. Cancer chemopreventive and antiangiogenic activities of xanthohumol from hop (Humuluslupulus L.) European Journal of Cancer Supplements. 2006; 4(1): 56. doi: 10.1016/ s1359-6349(06)80542-2

18. Albini $A$, Dell'Eva $R$, Vené $R$, et al. Mechanisms of the antiangiogenic activity by the hop flavonoid xanthohumol: NF-kappaB and Akt as targets. FASEB Journal. 2006; 20(3): 527-529. doi: 10.1096/fj.05-5128fje 